\title{
Survival and cause of death after traumatic spinal cord injury A long-term epidemiological survey from Denmark
}

\author{
A Hartkopp, H Brønnum-Hansen, A-M Seidenschnur and F Biering-Sørensen \\ Centre for Spinal Cord Injured, Neuroscience Centre, Rigshospitalet, Copenhagen University Hospital, and Danish \\ Institute for Clinical Epidemiology, Copenhagen, Denmark
}

Life expectancy among individuals with spinal cord injuries (SCI) has remained lower than in the normal population, even with optimal medical management. But significant improvement has been achieved, as will be illustrated in this retrospective study of an unselected group of traumatic survivors of SCI, dead or still living. There has been a complete follow-up over 4 decades, information being obtained from available medical records, death certificates, and post mortem records. The survey included a total of 888 individuals ( 713 men and 175 women) who had survived the injury and primary treatment and were rehabilitated at the centre for Spinal Cord Injured in Hornbæk, Denmark. At the end of the follow-up, 31st December 1992, 236 (197 men and 39 women) had died. The commonest causes of death were lung diseases, particularly pneumonia; suicide; and ischaemic heart disease. Among functionally complete tetraplegic individuals there was a recognizably high percentage of deaths from pneumonia, and among the least disabled individuals (Frankel class E) we found a high frequency of suicides. The Standardised Mortality Ratios (SMRs) were highest for septicaemia, followed by uraemia and pneumonia. A significant decrease in the overall mortality was observed from the first $(1953-1973)$ to the second half of the observation period (1972-1992). Similarly the survival curves for both men and women demonstrate that the gap in survival probability between the normal population and the SCI has diminished considerably from the early to the later period. Likewise, except for suicide and ischaemic heart disease, a decrease in SMRs was seen for all causes of death. In particular there were large decreases related to lung embolus, septicaemia, pneumonia, and uraemia. The patterns of causes of death in the study group begin to approximate those of the general population, though many cause-specific deaths for SCI remain substantially above the normal population. Continuous improvement in preventive measures as well as treatment procedures is still necessary.

Keywords: spinal cord injury; paraplegia; cause of death; mortality; survival curves; epidemiology

\section{Introduction}

There is general agreement in the literature that life expectancy among persons with spinal cord injury (SCI) remains below normal, even with optimal medical management. But since the Second World War the mortality rate has decreased dramatically. Previously, survival following a severe SCI was relatively rare because of untreatable pyelonephritis. ${ }^{1-4}$

The mortality before the Second World War has been reported to be as high as $60-80 \%$, decreasing to $30 \%$ in the $1960 \mathrm{~s}, 15 \%$ in the $1970 \mathrm{~s}$ and down to $6 \%$ in the 1980s. ${ }^{5}$ This decrease in the mortality rate can be primarily ascribed to the development of SCI treatment units, including well-trained specialised team-oriented rehabilitation, and regular follow-up

Correspondence: A Hartkopp visits. In addition, improved emergency medical services, the development of antibiotics etc. have contributed to the improved survival.

Until the mid 1970s, renal failure and other related urinary tract complications were reported to be the most frequent causes of death. ${ }^{2,3,6-9}$ More recent studies have suggested that most deaths during the acute phase of SCI have respiratory causes. ${ }^{1,10}$ Deaths at later stages are most often caused by respiratory complications, particularly pneumonia, which have surpassed urinary tract complications as the predominant cause of death. ${ }^{11-15}$ Other major causes of death reported are unintentional injuries and suicides, cardiovascular diseases and septicaemia. 1,11,16-20

Despite the large number of studies of post-SCI mortality, it is difficult to compare the available information because of differences in study population characteristics, statistical methodology, and 
sample size. The studies were carried out during different periods of time and in different countries with different medical services and follow-up routines. The study populations differed with regard to inclusion and exclusion criteria, especially age at the time of injury, level and completeness of the neurological effects of the SCI. Some studies are potentially biased by inhomogeneous follow-up reports, by restriction of the follow-up reports to deaths only, not taking the living SCI individuals into account, and by inclusion of patients in which the injuries happened long before the period of observation. ${ }^{14}$

In the last 4 decades the life expectancy of SCI individuals in Denmark as well as in other countries has increased remarkably. In this study we calculated Standardised Mortality Ratios (SMRs) for total mortality and for some specific causes of death among Danish SCI individuals, and evaluated the changes over time by comparing mortality in the two periods of injury, 1953 to 1971 and 1972 to 1990, respectively.

\section{Methods}

Sources of data for the background population (the total Danish population)

Information was obtained from The National Registry of Causes of Death, whose records include all deaths occurring since January 1, 1943, and from the general public records of vital statistics (Danmarks Statistik), which provided the basis for the calculation of mortality rates.

\section{Inclusion criteria}

This retrospective study includes all patients admitted to the Rehabilitation Hospital in Hornbæk, Denmark, with traumatic SCIs that occurred between 1st January 1953 and 31st December 1990. All deaths among these individuals have been registered up to 31st December 1992. The area of admission to the Rehabilitation Hospital has included East and South Denmark, Greenland, and the Faroe Islands. Patients requiring permanent respiratory support were not admitted during this period. Admission was restricted to patients with SCIs so severe that specialised treatment was necessary. ${ }^{21}$

\section{Data collection}

Information has been obtained from The Danish Central Population Registry which provides information on vital statistics for all Danish citizens. A unique personal identification code (a 10-digit code including the date of birth) makes it possible to trace any Danish citizen, irrespective of residence. Additional information has been obtained from available medical records, death certificates, and post mortem records. Information concerning gender, date of birth, and date of injury was collected. The neurological level is given as the last preserved segment at the time of injury, and the functional level according to Frankel et $a l^{22}$ at the last follow-up. Analyses were performed in relation to a combined neurological level and functional classification, ${ }^{22}$ ie functionally complete tetraplegia (cervical cord lesions and Frankel class $\mathrm{A}-\mathrm{C}$ ), functionally complete paraplegia (thoracic and lumbar cord lesions and Frankel class A-C), Frankel class D, and Frankel class E.

Table 1 Crude distribution of causes of death of spinal cord injured individuals by gender

\begin{tabular}{|c|c|c|c|c|c|c|}
\hline \multirow{2}{*}{$\begin{array}{l}\text { Cause of death } \\
\text { (ICD } 8 \text { numbers) }\end{array}$} & \multicolumn{2}{|c|}{ Men } & \multicolumn{2}{|c|}{ Women } & \multicolumn{2}{|c|}{ All } \\
\hline & no. & $(\%)$ & no. & $(\%)$ & no. & $(\%)$ \\
\hline Neoplasms $(140-239)$ & 14 & 7 & 2 & 5 & 16 & 7 \\
\hline Cardiovascular disease $(390-458)$ & 47 & 24 & 9 & 23 & 56 & 24 \\
\hline Ischaemic heart disease $(410-414)$ & 19 & 10 & 3 & 8 & 22 & 9 \\
\hline Cerebrovascular disease $(430-438)$ & 6 & 3 & 2 & 5 & 8 & 3 \\
\hline Lung embolus (450) & 6 & 3 & 0 & 0 & 6 & 3 \\
\hline $\begin{array}{l}\text { Other natural causes }(0-136,240- \\
\quad 389,460-796)\end{array}$ & 114 & 58 & 20 & 51 & 134 & 57 \\
\hline Septicaemia (38) & 7 & 4 & 1 & 3 & 8 & 3 \\
\hline Lung disease $(460-519)$ & 62 & 31 & 7 & 18 & 69 & 29 \\
\hline Pneumonia $(480-486)$ & 40 & 20 & 6 & 15 & 46 & 19 \\
\hline Digestive organs $(520-577)$ & 9 & 5 & 2 & 5 & 11 & 5 \\
\hline Urogenital system $(580-629)$ & 5 & 3 & 0 & 0 & 5 & 2 \\
\hline Uncertain $(780-796)$ & 27 & 14 & 9 & 23 & 36 & 15 \\
\hline Oliguria, anuria (786) & 2 & 1 & 0 & 0 & 2 & 1 \\
\hline Uraemia $(792)$ & 8 & 4 & 3 & 8 & 11 & 5 \\
\hline Accidents and suicide (E800-E999) & 22 & 11 & 8 & 21 & 30 & 13 \\
\hline $\begin{array}{l}\text { Accidents (E800-E949, E960- } \\
\text { E999) }\end{array}$ & 5 & 3 & 2 & 5 & 7 & 3 \\
\hline Suicide (E950 - E959) & 17 & 9 & 6 & 15 & 23 & 10 \\
\hline Total & 197 & 100 & 39 & 100 & 236 & 100 \\
\hline
\end{tabular}

ICD 8: International Classification of Disease, 8th edition 
The following details relating to their deaths have been registered: cause of death classified according to ICD 8 (International Classification of Disease, 8th edition), place of death, and whether an autopsy was performed. The 40 year observation period (19531992) has been divided in two corresponding to the year of injury: 1953-1971 and 1972-1990, ie the 1953-1971 material was observed until the end of 1973 and the 1972-1990 material until the end of 1992.

\section{Statistics}

Using The National Registry of Causes of Death, and the general public records of vital statistics (Danmarks Statistik), we calculated the survival rates of the Danish population of the same age for each gender in the calendar year that the patients sustained the SCI, thus enabling us to calculate the standardised mortality ratios (SMRs). SMR is the quotient of observed to expected number of deaths. Exactly $95 \%$ confidence limits of the SMRs were established, assuming deaths to be Poisson variables. ${ }^{23}$ We constructed life tables, with the time of SCI as time zero and death or end of follow-up as the finishing point. Thus patients were classified according to the year in which follow-up, emigration, or death was last reported. We used the statistical program package SAS (SAS Institute Inc., Cary, NC, USA) for the analyses. Specific life table analyses were carried out for comparison with results reported in previous studies.

\section{Results}

Three patients, known to be dead, could not be retrieved in the Registry of Causes of Death, ie the causes of death were not established, so they had to be categorized as dead of unknown causes. One could not be traced, probably owing to an inaccurate birth date on the death certificate. And we could not get the death ceritifcates of two patients who died abroad.

A total of 888 ( 713 men and 175 women) sustained their SCIs in the inclusion period (1953-1990). Of these, 359 (305 men and 54 women) sustained their SCIs in the first period $(1953-1971)$, while 529 (408 men and 121 women) sustained theirs in the last period $(1972-1990)$. At the end of follow-up, 31st December 1992, 236 (197 men and 39 women) were dead. For the first observation period, 52 (42 men and 10 women) were dead by the end of 1973 , and for the second observation period, 87 (69 men and 18 women) were dead by the end of 1992 .

The SCI population included 424 with cervical and 464 with thoracic/lumbar injuries.

For the whole period $(1953-1990)$ the median age at the time of injury was 28 years (men 27.5 years; women 31 years). For the first period $(1953-1971)$ the median age at injury was 27.5 years (men 27 years, range 1-80; women 31 years, range $2-75$ ). In the second period $(1972-1990)$ the median age at injury was 28.5 years (men 28 years, range $0-82$; women 30 years, range $0-84$ ).

Among those who died, $57.3 \%$ died in hospital and $35.7 \%$ at home. In $32.3 \%$ a post-mortem examination was performed.

Table 1 gives the crude distribution of causes of death specified by gender for all the SCI individuals who died before 1993. The predominant causes of death were lung diseases, and in particular pneumonia; suicide; and ischaemic heart diseases. Table 2 similarly gives the crude distribution of causes of death specified by the combined neurological level and functional

Table 2 Crude distribution of causes of death by a combined spinal cord level (Cervical (C); Thoracic (T); Lumbar (L)) and functional classification (Frankel A-E) for spinal cord injured individuals

\begin{tabular}{|c|c|c|c|c|c|c|c|c|}
\hline \multirow[b]{2}{*}{ Cause of death } & \multicolumn{2}{|c|}{$\begin{array}{c}\text { Tetraplegics } \\
\text { C/Frankel } A-C\end{array}$} & \multicolumn{2}{|c|}{$\begin{array}{c}\text { Paraplegics } \\
T-L / \text { Frankel } A-C\end{array}$} & \multicolumn{2}{|c|}{ Frankel $D$} & \multicolumn{2}{|c|}{ Frankel $E$} \\
\hline & no. & $(\%)$ & no. & $(\%)$ & no. & $(\%)$ & no. & $(\%)$ \\
\hline Neoplasms & 2 & 3 & 3 & 4 & 7 & 9 & 4 & 16 \\
\hline Cardiovascular disease & 9 & 13 & 14 & 20 & 27 & 36 & 6 & 24 \\
\hline Ischaemic heart disease & 2 & 3 & 5 & 7 & 10 & 14 & 5 & 20 \\
\hline Cerebrovascular disease & 2 & 3 & 2 & 3 & 4 & 5 & - & - \\
\hline Lung embolus & 1 & 1 & 1 & 1 & 3 & 4 & 1 & 4 \\
\hline Other natural causes & 50 & 75 & 44 & 64 & 32 & 43 & 8 & 32 \\
\hline Septicaemia & 2 & 3 & 6 & 9 & - & - & - & - \\
\hline Lung disease & 30 & 45 & 16 & 23 & 19 & 25 & 4 & 16 \\
\hline Pneumonia & 21 & 31 & 11 & 16 & 11 & 15 & 3 & 12 \\
\hline Digestive organs & 2 & 3 & 4 & 6 & 4 & 5 & 1 & 4 \\
\hline Urogenital system & 3 & 4 & 1 & 1 & 1 & 1 & - & - \\
\hline Uncertain & 11 & 16 & 14 & 20 & 8 & 11 & 3 & 12 \\
\hline Oliguria, anuria & - & - & 1 & 1 & - & - & 1 & 4 \\
\hline Uraemia & 4 & 6 & 6 & 9 & 1 & 1 & - & - \\
\hline Accidents and suicide & 6 & 9 & 8 & 12 & 9 & 12 & 7 & 20 \\
\hline Accidents & 1 & 1 & 2 & 3 & 4 & 5 & - & - \\
\hline Suicide & 5 & 8 & 6 & 9 & 5 & 7 & 7 & 28 \\
\hline Total & 67 & 100 & 69 & 100 & 75 & 100 & 25 & 100 \\
\hline
\end{tabular}


classification. Particularly noteworthy are the high percentages of death due to lung disease, especially pneumonia, among those with functionally complete tetraplegia, and the high frequency of suicides among the least disabled individuals (Frankel class E).

Table 3 shows SMRs for various causes of death specified by gender. The SMR was highest for septicaemia, followed by uraemia and pneumonia.
Examination of the confidence interval reveals that all cause-specific mortality rates, except for cancer, cardiovascular diseases, ischaemic heart diseases, cerebrovascular diseases, and accidents, were significantly higher for the SCI population compared with the Danish population at large. Tables 4 and 5 give the SMRs for the two observation periods, respectively. A significant decrease in the overall mortality

Table 3 Standardised mortality ratios (SMRs) for various causes of death by gender. Period of injury 1953-1990. End of follow-up: December 31, 1992. An empty cell indicate that only 0 or 1 death was recorded, why SMR is not given

\begin{tabular}{|c|c|c|c|c|c|c|}
\hline \multirow{2}{*}{ Cause of death } & \multicolumn{6}{|c|}{ SMR (95\% confidence limit) } \\
\hline & & Men & & Women & & All \\
\hline Neoplasms & 0.55 & $(0.30-0.91)$ & 0.39 & $(0.05-1.41)$ & 0.52 & $(0.30-0.84)$ \\
\hline Cardiovascular disease & 1.15 & $(0.85-1.53)$ & 1.13 & $(0.52-2.14)$ & 1.15 & $(0.87-1.49)$ \\
\hline Ischaemic heart disease & 0.68 & $(0.41-1.06)$ & 0.67 & $(0.14-1.96)$ & 0.68 & $(0.42-1.02)$ \\
\hline Cerebrovascular disease & 0.95 & $(0.35-2.07)$ & 1.10 & $(0.13-3.98)$ & 0.99 & $(0.43-1.94)$ \\
\hline Lung embolus & 14.3 & $(5.25-31.1)$ & & - & 11.4 & $(4.19-24.8)$ \\
\hline Other natural causes & 5.98 & $(4.93-7.18)$ & 5.25 & $(3.21-8.11)$ & 5.86 & $(4.91-6.94)$ \\
\hline Septicaemia & 136 & $(54.8-281)$ & & - & 125 & $(54.0-246)$ \\
\hline Lung disease & 10.2 & $(7.79-13.0)$ & 6.21 & $(2.50-12.8)$ & 9.54 & $(7.42-12.1)$ \\
\hline Pneumonia & 29.5 & $(21.0-40.1)$ & 13.8 & $(5.06-30.0)$ & 25.6 & $(18.8-34.2)$ \\
\hline Lung disease excl. pneumonia & 4.63 & $(2.90-7.02)$ & & - & 4.23 & $(2.68-6.35)$ \\
\hline Digestive organs & 2.56 & $(1.17-4.87)$ & 3.23 & $(0.39-11.7)$ & 2.66 & $(1.33-4.77)$ \\
\hline Urogenital system & 4.61 & $(1.50-10.7)$ & & - & 3.68 & $(1.20-8.60)$ \\
\hline Uncerain & 8.56 & $(5.64-12.5)$ & 12.6 & $(5.77-24.0)$ & 9.31 & $(6.52-12.9)$ \\
\hline Uraemia & 84.9 & $(36.6-167)$ & 95.0 & $(19.6-278)$ & 87.4 & $(43.6-156)$ \\
\hline Uncertain excl. uraemia & 6.21 & $(3.74-9.70)$ & 8.81 & $(3.23-19.2)$ & 6.68 & $(4.32-9.86)$ \\
\hline Urogenital system and uraemia & 11.0 & $(5.87-18.8)$ & 9.91 & $(2.04-28.9)$ & 10.8 & $(6.17-17.5)$ \\
\hline Accidents and suicide & 2.18 & $(1.36-3.29)$ & 6.01 & $(2.60-11.8)$ & 2.62 & $(1.77-3.74)$ \\
\hline Accidents & 0.89 & $(0.29-2.08)$ & 2.50 & $(0.30-9.04)$ & 1.09 & $(0.44-2.25)$ \\
\hline Suicide & 3.78 & $(2.20-6.05)$ & 11.3 & $(4.14-24.6)$ & 4.57 & $(2.90-6.86)$ \\
\hline Total & 2.07 & $(1.79-2.38)$ & 2.15 & $(1.53-2.94)$ & 2.08 & $(1.83-2.37)$ \\
\hline
\end{tabular}

Table 4 Standardised mortality ratios (SMRs) for various causes of death by gender. Period of injury 1953-1971. End of follow-up: December 31, 1973. An empty cell indicate that only 0 or 1 death was recorded, why SMR is not given

\begin{tabular}{|c|c|c|c|c|c|c|}
\hline Cause of death & \multicolumn{6}{|c|}{ SMR (95\% condidence limit) } \\
\hline Neoplasms & & - & & - & & - \\
\hline Cardiovascular disease & 3.19 & $(1.38-6.29)$ & 3.50 & $(0.09-19.5)$ & 3.22 & $(1.47-6.12)$ \\
\hline Ischaemic heart disease & & - & & - & 1.08 & $(0.13-3.91)$ \\
\hline Cerebrovascular disease & & - & & - & & - \\
\hline Lung embolus & 131 & $(27.1-384)$ & & - & 107 & $(22.1-313)$ \\
\hline Other natural causes & 26.2 & $(17.7-34.4)$ & 40.6 & $(16.3-83.6)$ & 28.1 & $(19.8-38.7)$ \\
\hline Septicaemia & 542 & $(65.7-1959)$ & & - & 720 & $(148-2103)$ \\
\hline Lung disease & 47.8 & $(26.1-80.2)$ & 65.3 & $(7.91-236)$ & 49.5 & $(28.3-80.4)$ \\
\hline Pneumonia & 92.2 & $(37.1-190)$ & 164 & $(19.9-594)$ & 102 & $(46.7-194)$ \\
\hline Lung disease excl. pneumonia & 32.3 & $(13.0-66.5)$ & & - & 29.8 & $(12.0-61.3)$ \\
\hline Digestive organs & 13.2 & $(2.73-38.6)$ & & - & 11.6 & $(2.40-33.9)$ \\
\hline Urogenital system & 22.8 & $(4.71-66.8)$ & & - & 18.7 & $(3.85-54.6)$ \\
\hline Uncertain & 67.2 & $(27.0-138)$ & 247 & $(50.9-721)$ & 86.0 & $(41.2-158)$ \\
\hline Uraemia & 1548 & $(568-3369)$ & & - & 1518 & $(610-3127)$ \\
\hline Uncertain excl. uraemia & & - & 175 & $(21.2-633)$ & 26.9 & $(5.54-78.5)$ \\
\hline Urogenital system and uraemia & 66.6 & $(30.4-126)$ & & - & 60.5 & $(29.0-111)$ \\
\hline Accidents and suicide & 2.37 & $(0.49-6.91)$ & 21.8 & $(2.63-78.6)$ & 3.68 & $(1.19-8.58)$ \\
\hline Accidents & & - & & - & 2.39 & $(0.29-8.63)$ \\
\hline Suicide & 4.17 & $(0.51-15.1)$ & & - & 5.74 & $(1.18-16.8)$ \\
\hline Total & 6.47 & $(4.66-8.74)$ & 12.1 & $(5.81-22.3)$ & 7.10 & $(5.31-9.32)$ \\
\hline
\end{tabular}


was observed from the first to the second observation period. Except for suicide and ischaemic heart disease a decrease in SMR was seen for all causes of death. In particular the decreases related to lung embolus, septicaemia, pneumonia, and uraemia are noteworthy.

SMRs for cervical and thoracic/lumbar lesions, respectively, are given in Table 6 . No differences of SMRs were found between cervical and lower lesions. Especially interesting is the fact that no difference was found with respect to lung diseases.

Figure 1 gives the survival probability of the SCI individuals, men and women, and the matching general populations for the whole period. A specific period of cumulative probability of survival, (eg 25 years) can be obtained from the figures. The 25 year probabilities of survival for SCI men and women were $60.6 \%$ and $66.7 \%$ respectively. The same figures for the general population of men and women were $66.9 \%$ and $76.5 \%$ respectively. Likewise the number of years of survival can be read from the figures. Thus $70 \%$ of the population of SCI, men and women, were still alive after 19.5 and nearly 22 years, respectively. The corresponding duration of survival for the general population of men and women were 23.5 and 29 years, respectively. The survival curves were not followed longer than 30 years since observations of more than 30 years of survival are scarce.

Figure 2 gives the survival probability of the SCI individuals and the matching general population for men and women for the two periods during which the injuries were sustained. (The 10 year probability of survival for SCI men and women in the first and second period were for men $78.7 \%$ and $86.8 \%$, for

Table 5 Standardised mortality ratios (SMRs) by gender and cause of death. Period of injury 1972-1990. End of follow-up: December 31, 1992. An empty cell indicate that only 0 or 1 death was recorded, why SMRs are not given

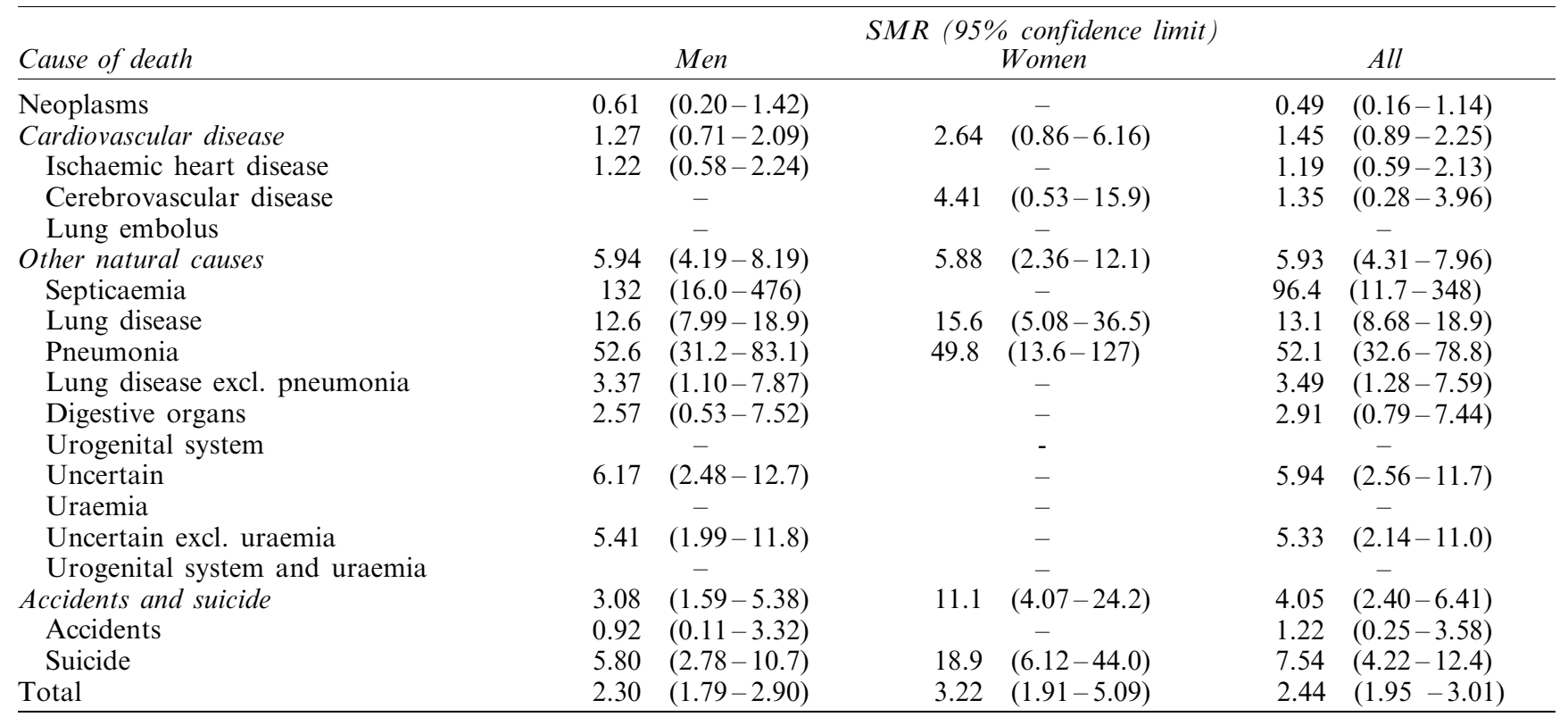

Table 6 Standardised mortality ratios (SMRs) for various causes of deaths by level of spinal cord lesion: Cervical versus thoracic/lumbar. Period of injury 1953-1990. End of follow-up: December 31, 1992

\begin{tabular}{|c|c|c|c|c|}
\hline \multirow{3}{*}{$\frac{\text { Causes of death }}{\text { Neoplasms }}$} & \multicolumn{4}{|c|}{ SMR (95\% Confidence limit) } \\
\hline & \multicolumn{2}{|c|}{ Cervical lesion } & \multicolumn{2}{|c|}{ Thoracic/lumbar lesion } \\
\hline & 0.64 & $(0.32-1.15)$ & 0.37 & $(0.12-0.85)$ \\
\hline Cardiovascular disease & 1.07 & $(0.72-1.53)$ & 1.26 & $(0.82-1.84)$ \\
\hline Other natural causes & 5.86 & $(4.60-7.35)$ & 5.85 & $(4.47-7.53)$ \\
\hline Septicaemia & 55.4 & $(6.70-200)$ & 215 & $(79.0-469)$ \\
\hline Lung disease & 9.95 & $(7.17-13.5)$ & 8.97 & $(5.91-13.0)$ \\
\hline Pneumonia & 26.2 & $(17.4-37.9)$ & 24.8 & $(14.7-39.2)$ \\
\hline Lung disease excl. pneumonia & 4.44 & $(2.43-7.45)$ & 3.94 & $(1.80-7.48)$ \\
\hline Accidents and suicide & 3.04 & $(1.77-4.87)$ & 2.22 & $(1.18-3.80)$ \\
\hline Total & 2.09 & $(1.75-2.48)$ & 2.07 & $(1.69-2.51)$ \\
\hline
\end{tabular}


women $72.1 \%$ and $86.9 \%$, respectively. The corresponding probabilities for the general population in the first and second period were for men $93.7 \%$ and $92.5 \%$, for women $96.7 \%$ and $94.5 \%$ respectively.

The only very slight initial decrements of the curves in Figures 1 and 2 are a consequence of the inclusion criteria, ie we included only the SCI individuals who had survived the acute phase after the injury.

\section{Discussion}

One limitation to our findings might be the fact that the study population had already survived the immediate injury and the period of emergency and primary treatment (days to several months) when admitted to the Rehabilitation Hospital. On the other hand this omission of the primary deaths makes the survival information more relevant when considering the individuals who come as far as entering the rehabilitation phase after their SCI.

There is a noticeable trend towards improvement in life expectancy for SCI patients from the beginning of the observation period until its end. In Figure 2 it is clearly demonstrated that for men as well as women the gap in survival probability between the normal population and the SCI is considerably diminished from the $50 \mathrm{~s}$ and $60 \mathrm{~s}$ to the $70 \mathrm{~s}$ and $80 \mathrm{~s}$. The significance of this may be even greater, when considering that the individuals in the first period were a selected group in the sense that they were able to survive with less developed emergency medical services, and, additionally, surviving a longer period between the day of injury to admittance to the Rehabilitation Hospital in Hornbæk. In the second observation period SCI individuals were admitted to the centre as soon as they were out of intensive care.
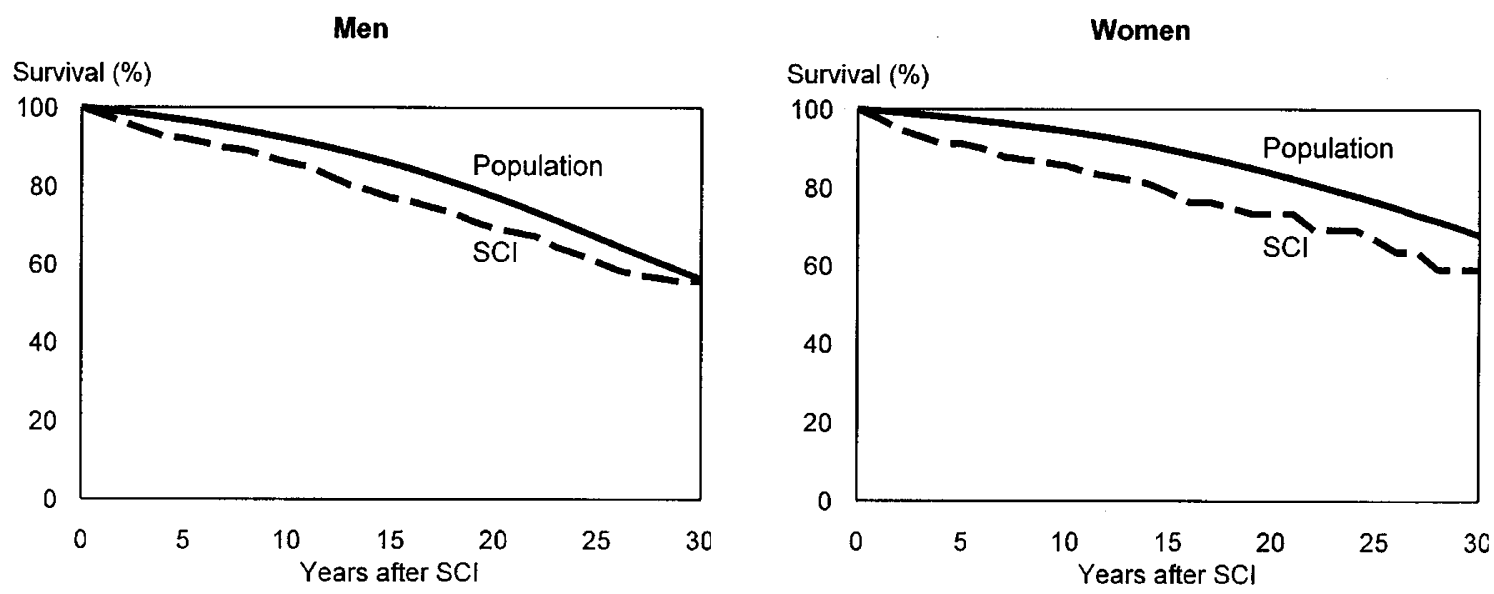

Figure 1 Survival probability of spinal cord injured individuals and of the matched general population. Period of injury: 1953-1990. End of follow-up: December 31, 1992
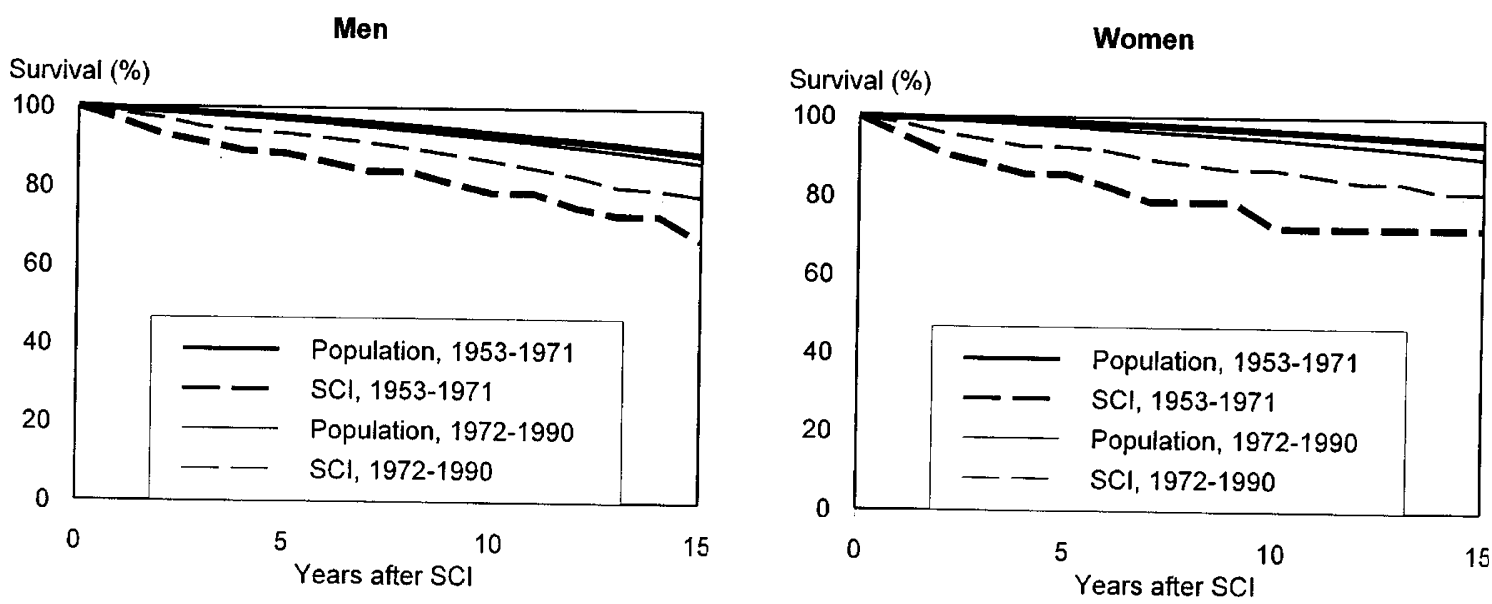

Figure 2 Survival probability of spinal cord injured individuals and of the matched general population. Periods of injury: 1953-1971. End of follow-up: December 31, 1973. 1972-1990. End of follow-up: December 31, 1992 
The lower survival probability for the normal population in the second period $(1972-1990)$ can be explained by the fact that the age when sustaining the SCI has been increasing slightly during the last 40 years. Therefore the age of the matching normal population had to be higher also at time zero, thus contributing to a lower survival probability.

In general our survival probabilities throughout the whole study period are similar to the results reported by others ${ }^{14,17,24-27}$ (Table 7), but as already pointed out in the introduction it is very difficult to compare the different studies.

DeVivo et al, had reported several studies giving cumulative survival probabilities for various year spans. $^{25-27}$ Similarly, in their studies all SCI individuals were treated in Rehabilitation Hospitals within a year from the date of injury and had survived $24 \mathrm{~h}$ when included. But it is not clear whether all SCI individuals among the residents in the particular area had the opportunity to stay in one of the Rehabilitation Hospitals. If not there is a bias in their results, and another bias comes from losses to follow-up, although the population sizes are impressive. DeVivo et $a l,{ }^{26}$ found an estimated 12 year cumulative survival probability of $85.1 \%$. Because of the problems arising from the losses to follow-up the authors had also calculated the worst $(78.2 \%)$ and best $(85.7 \%) 12$ year cumulative survival probability, presuming that all the losses in follow-up had either died or survived until the time of the end of follow-up. The corresponding 12 year survival probability for our study $(83.2 \%)$ lies between these two extremes. As all hospital treatment and rehabilitation in Denmark is free of charge, we have most probably included all SCI individuals in the 'catchment' area.

In the 12 months of 1971 , Kraus et al, ${ }^{14}$ were able to include all SCI individuals in the 'catchment' area. The 5--year cumulative survival probability was calculated for all SCI individuals who survived for more than $24 \mathrm{~h}$. Their figures are somewhat lower than ours (Table 7). However, we assess the 5--year cumulative survival probablity for SCI individuals in Kraus et al, study ${ }^{14}$ who had survived one week, to be $88 \%$. One week of delay between SCI and inclusion in the survival study is similar to the protocol used in our study and after this adjustment the survival probabilities in the two studies are similar.

Mesard et $a l,{ }^{24}$ found an impressively high 10 year cumulative survival probability in their study from the mid fifties to the mid sixties, ranging from $80 \%$ for those with tetraplegia to $86 \%$ for those with paraplegia, although the individuals included survived the first 3 months.

Geisler et al's study from the seventies ${ }^{17}$ excluded all deaths within 12 months of trauma. They calculated the excess death rate to 15.2 extra deaths per 1000 $\mathrm{SCI} /$ years. We have carried out a similar calculation on our data for comparison, giving an excess death rate of 24 for the first period and 8.6 for the second period of injury (Table 7). It seems that the figures of
Geisler et al which were obtained from the last years of our first period and the first years of our second period, also coincide nicely with the figures calculated in our study. This also emphasises the importance that the time of the study period since survival has improved considerably in recent years.

Some of the SMRs in our study have been calculated on the basis of few deaths (Table 1) and should therefore be interpreted with caution. Especially some of the extremely high SMRs, eg for septicaemia and uraemia. Septicaemia usually results from severe infected pressure sores or from urinary tract infections.

This study did not confirm the previously suggested increased mortality from urinary bladder cancer. ${ }^{28,29}$ This complication appears to be associated with longterm use of indwelling bladder catheters. The introduction of intermittent catheterisation in recent decades may well have reduced the risk of the development of this neoplasm.

It has earlier been found that death due to cardiovascular disease is increasing due to longer post-injury survival times and the sedentary lifestyle of SCI individuals. ${ }^{16,30-32}$ Our data did not support this suggestion, nor did the recent Stockholm SCI Study find an increased risk of cardiac disease. ${ }^{33}$

Our results did not confirm the previously suggested higher mortality caused by lung disease among the cervical lesioned individuals compared to individuals with lower lesions. $1,10,11,16$ On the other hand we found a high crude percentage of death of lung diseases, in particular pneumonia, among those with functionally complete tetraplegia. This discrepancy may be explained by the fact that the SMRs in our study included patients with both complete and incomplete lesions. A complete cervical cord injury markedly reduces respiratory function, corresponding to absence of abdominal and intercostal muscles. Also increased retention of secretions in the respiratory tract, bronchospasm and inability to cough and breathe effectively causes retained secretions and atelectasis and favours the development of bronchitis and bronchopneumonia. ${ }^{10}$

An unexpected and very interesting finding in our study was the high frequency of suicide in Frankel class E, which implies nearly complete recovery. This counter-intuitive lack of correlation between level of neurological loss and psychosocial adjustment has previously been partly demonstrated. ${ }^{34}$ Less physical and social support is provided to individuals in Frankel class E, which, combined with over optimistic hopes of recovery and increased expectations, may result in a heavier burden of coping. Some spasticity and sexual problems may occur, including impotence for men. ${ }^{35}$ It looks as if the Frankel class E individuals adjust insufficiently to their loss, which can lead to frustration, depression, and suicide.

Although the mortality rates for SCI individuals have declined dramatically in recent years and may approach those of the non-paralysed population, there 


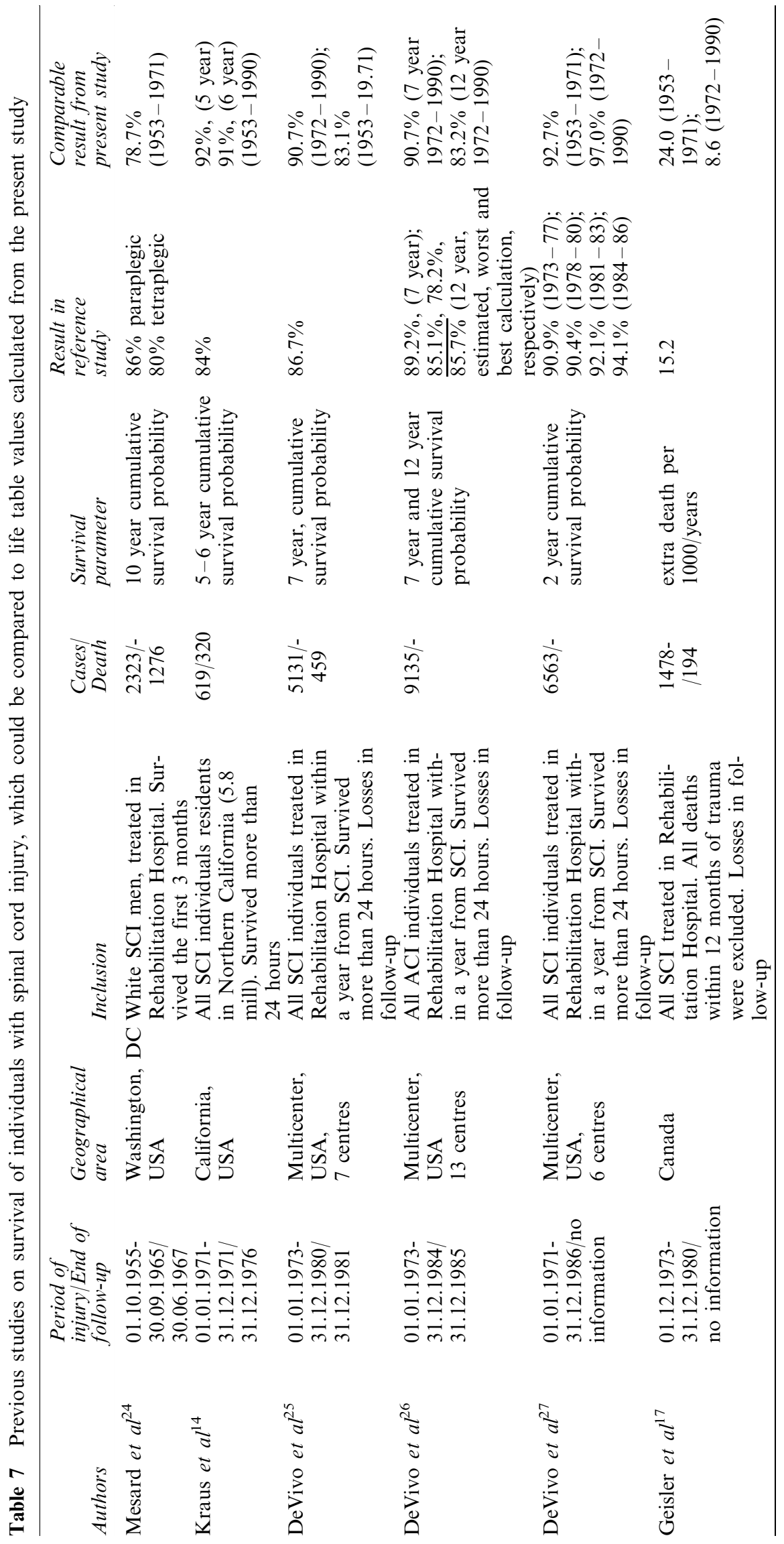


are still some cause-specific mortality rates which remain substantially above normal. Death due to septicaemia, pneumonia, and suicide is still much too frequent.

Infection, primarily pneumonia, is a major cause of mortality and morbidity in SCI individuals, in particular in those with functionally complete tetraplegia. SCI individuals are also predisposed to infections from the urinary tract and from pressure sores. Thus continuous improvements in preventive measures as well as in treatment procedures are still necessary.

As the life expectancy for individuals with SCI increases, attention has been focusing on the relatively high rate of suicide among individuals with SCI. ${ }^{2,6,9,15,18,36-38}$ Suicide even appears to be more frequent in recent years. Both the high crude suicide rate and the high SMRs, especially in the second period, were documented in this study. Increased awareness is needed among rehabilitation staff, general practitioners, patients, and their families. Frank discussions of the risk of suicide must take place, as well as clinical recommendations to improve the coping skills. The necessary social support should be provided. All of these and of other essential measures should be taken to provide meaningful activities in order to improve the quality of life. ${ }^{39-43}$ The preservation of family structure and open communication is fundamental. Better diagnosis and treatment of depression is required and the detection of psychological adjustment difficulties is important.

Adequate initial care and a life-long follow-up system of physical as well as psychological status are important for the proper treatment of SCI individuals.

\section{References}

1 DeVivo MJ et al. Cause of death for patients with spinal cord injuries. Arch Intern Med 1989; 149: 1761 - 1766.

2 Geisler WO, Jousse AT, Wynne Jones M. Survival in traumatic transverse myelities. Paraplegia 1977; 14: $262-275$.

3 Freed MM, Bakst HJ, Barrie DL. Life expectancy, survival rates, and causes of death in civilian patients with spinal cord trauma. Arch Phys Med Rehabil 1966; 47: 457-463.

4 Tribe CR. Causes of death in the early and late stages of paraplegia. Paraplegia 1963; 1: 19-47.

5 Ducker TB. Treatment of spinal cord injury. [Editorial]. New Eng $J$ Medicine 1990; 322(20): 1459 - 1461

6 Jousse AT, Wynne Jones M, Breithaupt DJ. A follow-up study of life expectancy and mortality in traumatic transverse myelitis. Proc Annu Clin Spinal Cord Inj Conf 1967; 16: 198-202.

7 Damanski M, Gibson N. The upper urinary tracts in the paraplegic: A long-term survey. Br J Urol 1955; 28: 19-48.

8 Hackler RH. A 25-year prospective mortality study in the spinal cord injured patient: comparison with the long-term living paraplegic. J Urol 1977; 117: 486-488.

9 Nyquist RH, Bors E. Mortality and survival in traumatic myelopathy during nineteen years, from 1946 to 1965 . Paraplegia 1967; 5: $22-48$.

10 Kiwerski JE. Factors contributing to the increased threat to life following spinal cord injury. Paraplegia 1993; 31: $793-799$.

11 DeVivo MJ, Black KJ, Stover SL. Causes of death during the first 12 years after spinal cord injury. Arch Phys Med Rehabil 1993; 74: $248-254$
12 Frisbie JH, Kache A. Increasing survival and changing causes of death in myelopathy patients. J Am Paraplegia Soc 1983; 6: $51-$ 56.

13 Ravichandran G, Silver JR. Survival following traumatic tetraplegia. Paraplegia 1982; 264-269.

14 Kraus JF, Franti CE, Borhani NO, Riggins RS. Survival with an acute spinal-cord injury. J Chronic Dis 1979; 32: 269-283.

15 Wilcox NE, Stauffer ES. Follow-up of 423 consecutive patients admitted to the spinal cord centre, Rancho Los Amigos hospital, 1 January to 31 December 1967. Paraplegia 1972; 10: 115-122.

16 Whiteneck GG et al. Mortality, morbidity, and psychosocial outcomes of persons spinal cord injured more than 20 years ago. Paraplegia 1992; 30: 617-630.

17 Geisler WO, Jousse AT, Wynne-Jones M, Breithaupt D. Survival in traumatic spinal cord injury. Paraplegia 1983; 21: 364-373.

18 Le CT, Price M. Survival from spinal cord injury. J Chron Dis 1982; 35: $487-492$

19 Borges PM, Hackler RH. The urologic status of the Vietnam war paraplegic: a 15-year prospective follow-up. J Urol 1982; 127: $710-711$.

20 Silver JR, Gibbon NO. Prognosis in tetraplegia. Br Med J 1968; 4: $79-83$.

21 Biering-Sørensen F, Pedersen V, Clausen S. Epidemiology of spinal cord lesions in Denmark. Paraplegia 1990; 28: $105-$ 118.

22 Frankel HL et al. The value of postural reduction in the initial management of closed injuries of the spine with paraplegia and tetraplegia. I. Paraplegia 1969; 7: 179-192.

23 Ulm K. A simple method to calculate the confidence interval of a standardized mortality ratio (SMR). Am J Epidem 1990; 131: $373-375$.

24 Mesard L, Carmody A, Mannarino E, Ruge D. Survival after spinal cord trauma. A life table analysis. Arch Neurol 1978; 35: $78-83$.

25 DeVivo MJ et al. Seven-year survival following spinal cord injury. Arch Neurol 1987; 44: 872-875.

26 DeVivo MJ, Stover SL, Black KJ. Prognostic factors for 12-year survival after spinal cord injury [published erratum appears in Arch Phys Med Rehabil 1992 Dec; 73(12): 1146]. Arch Phys Med Rehabil 1992; 73: 156-162.

27 DeVivo MJ et al. Trends in spinal cord injury demographics and treatment outcomes between 1973 and 1986 [published erratum appears in Arch Phys Med Rehabil 1992 Dec; 73(12): 1146]. Arch Phys Med Rehabil 1992; 73: 424-430.

28 El-Masri WS, Fellows G. Bladder cancer after spinal cord injury. Paraplegia 1981; 19: 265-270.

29 Sugarman B. Medical complications of Spinal cord Injury. Quart $J$ Med 1985; New Series 54: 3-18.

30 Ohry A, Brooks ME, Bar-On Z. Aging Issues in spinal cord injured patients. Crit Rev Phys Rehabil Med 1992; 4(1,2): 27 - 35 .

31 Yekutiel $\mathrm{M}$ et al. The prevalence of hypertension, ischemic heart disease and diabetes mellitus in traumatic SCIP and amputees. Paraplegia 1989; 27: 58.

32 Maki KC et al. Associations between serum lipids and indicators of adiposity in men with spinal cord injury. Paraplegia 1995; 33: $102-109$.

33 Levi R, Hultling C, Seiger A. The Stockholm Spinal Cord Study. 3. Health-related issues of the Swedish annual level-of-living survey in SCI subjects and controls. Paraplegia 1995; 33: $726-$ 730.

34 Richards JS. Psychologic adjustment to spinal cord injury during first postdischarge year. Arch Phys Med Rehabil 1986; 67: $362-$ 365.

35 Glass CA. Applying functional analysis to psychological rehabilitation following spinal cord injury. $J$ Am Paraplegia Soc 1992; 15: $187-193$.

36 Charlifue SW, Gerhart KA. Behavioral and demographic predictors of suicide after traumatic spinal cord injury. Arch Phys Med Rehabil 1991; 72: 488-492.

37 DeVivo MJ, Black KJ, Richards JS, Stover SL. Suicide following spinal cord injury. Paraplegia 1991; 29: 620-627.

38 Geisler WO, Jousse AT, Wynne Jones M, Breithaupt D. Survival in traumatic spinal cord injury. Paraplegia 1983; 21: 364-373. 
39 Krause JS, Kjorsvig JM. Mortality after spinal cord injury: a four-year prospective study [published erratum appears in Arch Phys Med Rehabil 1992 Aug;73(8):716]. Arch Phys Med Rehabil 1992; 73: $558-563$.

40 Hammell KR. Psychosocial outcome following spinal cord injury. Paraplegia 1994; 32: $771-779$.

41 Stensman R. Adjustment to traumatic spinal cord injury. A longitudinal study of self-reported quality of life. Paraplegia 1994; 32: $416-422$.
42 Clayton KS, Chubon RA. Factors associated with the quality of life of long-term spinal cord injured persons. Arch Phys Med Rehabil 1994; 75: $633-638$.

43 Krause JS. Longitudinal changes in adjustment after spinal cord injury: a 15-year study. Arch Phys Med Rehabil 1992; 73: $564-$ 568 